\title{
Incidence \& Drug Use in Chronic Suppurative Otitis Media (Csom) In Opd E.N.T at Teritary Care Teaching Hospital
}

\author{
Sanjeeva Kumar Goud ${ }^{1}$.T, Rakesh Kumar ${ }^{2}$, Vithal G. Patil ${ }^{1}$, \\ Anup bhusal ${ }^{1}$, Rajlakshmi $\mathrm{kh}^{2}$.Snigdha senpaty ${ }^{2,}$ Lalan $\mathrm{H} . \mathrm{N}^{1}$. \\ Department of Pharmacology ${ }^{1}$, Department of otorhinology ${ }^{2}$ \\ M.G.M. Medical College and Hospital, Navi Mumbai.
}

\begin{abstract}
:
Background: The aim of this study was to evaluate the incidence \& drug use CSOM in outpatient Department of Otolaryngology in a tertiary care teaching hospital.

Methods: Observational study conducted at the M.G.M. medical college and hospital, NaviMumbai.A period of 6 months.

Results: A total of around 300 patients prescription were collected over a period of 6 months out of these 112 patients were suffering from CSOM, so data analysed for these patients of CSOM. The number of male and female patients were 48(42.85) and 64(57.14) respectively. The CSOM infections were more common in the age group of 11-40 yr who accounted for 74.10\% (112) of the total patients. Total no. of drugs prescribed 276. Mean no. of drugs per prescriptions3.13. Route of drug administration - Oral route 181 (65.57\%) Topical route 95(34.42\%)were prescribed. Total no. of antibiotics prescribed165(59.78\%),most commonly prescribed drug was Paracetamol+Anhydrasecaffine+Phenylehrine+ Chlorpheneramine Maleate 71(25.72\%) , Chloramphenicol+ Polymyxin-B sulphate+ Dexmethasone 53(19.20\%), Amoxicillin + Clavulanic acid 46 (16.66\%) prescribed.Drugs prescribed by brand name were 100\%. The average cost per prescription was Rs.137.50.

Conclusion: The present study showed that combination of Paracetamol + Anhydrase caffine + Phenylehrine + Chlorpheneramine Maleate, Chloramphenicol+ Polymyxin-B sulphate+ Dexmethasone, amoxicillin +clavulanic acid, were mostly commonly prscribed. Prescriptions by brand name are matters of concern.
\end{abstract}

Keywords: E.N.T infections, drug utilization, antimicrobials, topical.

\section{Introduction}

Otitis Media is inflammation of the middle ear cleft irrespective of etiology and pathogenesis. Sources of infection in Otitis Media is mainly dependent on the route by which the infection reaches the middle ear and the chief route by which this occurs is the Eustachian Tube. ${ }^{(1)}$ Causes in such cases is nasopharyngeal disease and in children it is usually the adenoids, Tonsilloadenoiditis, Rhinosinusitis. The causative infection may be in the nose, paranasal sinuses, or in the oropharynx. ${ }^{(2)}$ Chronic Suppurative Otitis Media (CSOM) is a persistent disease of middle ear, which is capable of causing severe destruction and sequelae with manifestation of Deafness,Discharge and Perforation. ${ }^{(3)}$ Most common organism found in CSOM are Pseudomonas aeruginosa, Staphylococcus aureus, Proteus mirabilis, Klebsiellapneumonae,E.coli, Aspergillussps. and Candida. ${ }^{(4)}$ However, due to increased and irrational use of wide-spectrum antibiotics, the resistance in the bacterial isolates has become very common along with emergence of multiple strains of bacteria. ${ }^{(5)}$

CSOM is a serious healthcare concern worldwide, not only because of the distress it causes to the patient and their family but also because of the substantial economic burden quantifiable and unquantifiable, financial and non financial losses in productivity and reduced quality of life which it imposes on the affected individuals. ${ }^{(6)}$ Poverty, poor hygiene, malnutrition and lack of medical facilities, frequent upper respiratory tract infections, low socioeconomic status have been suggested as a basis for the widespread prevalence of CSOM. ${ }^{(7)}$

The aims of managing the chronic discharging ear are early detection and timely, appropriate intervention to eradicate the disease permanently or to reduce its effects such as ear discharge, hearing loss and other complications like intracranial extension, if eradication is not possible. ${ }^{(6)}$ This can be solved by regular aural toileting, antibiotic treatment, middle ear reconstruction and the use of hearing aids for rehabilitation.

The International Network for the Rational Use of Drugs (INRUD) was established in 1989 to promote the rational use of drugs in developing countries. Various indicators were developed by INRUD in collaboration with WHO that provided objective indices to allow for assessment of drug use practices. ${ }^{(9)}$ Still, there is a need for data on both antibiotic use and determinants of use from all the regions of the world. Therefore, it is imperative to evaluate and monitor the drug utilization patterns from time to time, to enable suitable modifications in prescribing patterns to increase the therapeutic benefit and decrease the adverse effects to optimize the medical services for the patients. ${ }^{(10)}$ Drug use evaluation is ongoing, authorized and systemic 
quality improvement processes, which is designed to review the drugs which are prescribed to the patients, provide a right feedback to the clinician/other relevant groups, develop criteria and standards that describe optimal drug use, promote appropriate drug use through education and counsel the patients. The present study was aimed evaluate the pattern of drug usage in CSOM

\section{Study Objectives}

2.1.AimsTo study the incidence and drugs usage pattern in CSOM in ENT OPD of tertiary care teaching hospital

2.2 .Study design- Observational, Cross-sectional study.

2.3 Place of study-In E.N.T OPD, MGM Hospital, Kamothe, NaviMumbai.Questionnaire was specifically designed for the study. It included patient particulars, diagnosis, drug details. Cost ofdrugs was calculated as per price list available in the updated standard pharmacopeia books (MIMS, CIMS).

2.4 .Duration of study:

The duration of study was 6 months (16-6-2013 to 16-12-2013). The study was approved by the Institutional Ethical Committee. Written consent was obtained from the patients before their participation in the study.

\subsection{Evaluated parameters:}

2.5.1. Average number of drugs per encounter.

2.5.2. Percentage of drugs prescribed by generic name.

2.5.3. Percentage of encounters with an antibiotic prescribed.

2.5.4. Percentage of encounters with concomitant medications prescribed.

2.5. Percentage of patients treated without drugs.

2.5.6. Average drug cost per prescription.

\section{Result}

A total of around 300 patients prescription were collected over a period of 6 . Out of these, CSOM was the most common disease which is accounted for $37.33 \%$ (112) followed by Allergic rhinitis $66(22 \%)$ pharyngitis 42 (14\%),ASOM $36(12 \%)$, Tonsillitis 30 (10\%), Rhinosinusitis $14(4.66 \%)$, and. A total of 112 patients were suffering from CSOM, so data analysed for these patients of CSOM.Fig- 1 showed Pattern of diseases in ENT POD, CSOM was the most common disease which is accounted for 37.33\%(112) followed by Allergic rhinitis $66(22 \%)$ pharyngitis $42(14 \%)$

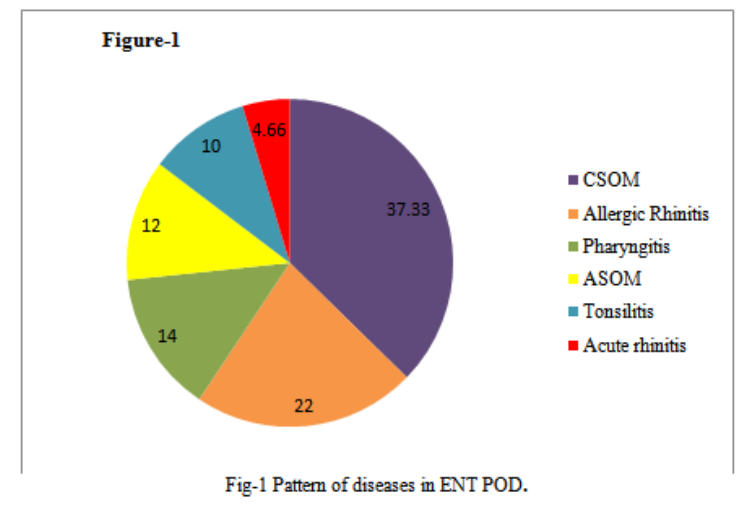

Fig-1 Pattern of diseases in ENT POD.

Table 1: Age and sex distribution of patients

\begin{tabular}{|l|l|l|l|}
\hline Age & Male & Female & Percentage \\
\hline Below 10 & 01 & 4 & 5 \\
\hline $11-20$ & 10 & 16 & 26 \\
\hline $21-30$ & 14 & 21 & 35 \\
\hline $31-40$ & 11 & 11 & 22 \\
\hline $41-50$ & 04 & 09 & 13 \\
\hline $51-60$ & 03 & 03 & 06 \\
\hline $61-70$ & 03 & - & 03 \\
\hline $71-80$ & 02 & - & 02 \\
\hline Total $(\%)$ & 48 & 64 & 112 \\
\hline
\end{tabular}


Table-1 shows the distribution of CSOM diseases in different age groups. Among the 112 CSOM infections patients, the number of male and female patients who attended the OPD was 48(42.85) and 64(57.14) respectively. The CSOM infections were more common in the age group of 11- $40 \mathrm{yr}$ who accounted for $74.10 \%$ (112) of the total patients.

During the study it was observed CSOM infections wereCSOM Safe active patients- 63(56.25\%), CSOM Inactive patients - 24(21.42\%), CSOM Unsafe patients -25(22.32\%). Fig - 2 Showed Pattern of CSOM infections, the most common infections which is accounted for CSOM Safe active patients - 63(56.25\%) followed by CSOM Unsafe patients $-25(22.32 \%)$

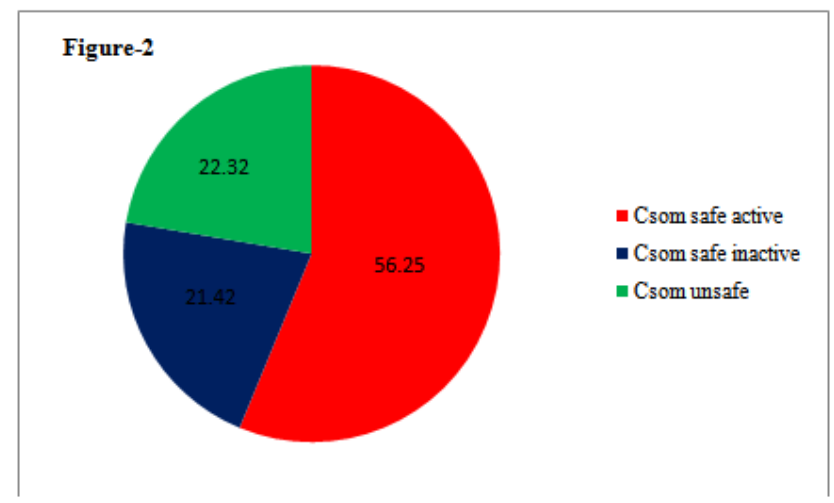

Fig-2 Pattern of CSOM infections.

Table 2 Prescribedpatterns of drugs:

\begin{tabular}{|l|l|}
\hline Parameter & No. and (\%) \\
\hline Total no. of prescriptions & 112 \\
\hline Total no. of drugs prescribed & 276 \\
\hline Mean no. of drugs per prescriptions & 3.13 \\
\hline Total no. of patients treated without drugs & $24(21.42 \%)$ \\
\hline Total no. of antibiotics prescribed & $165(59.78 \%)$ \\
\hline Mean no. of antibiotics per prescriptions & 1.87 \\
\hline No. of drugs prescribed by generic name & $0 \%$ \\
\hline No. of drugs prescribed by brand name & $100 \%$ \\
\hline Oral route of drug administration & $181(65.57 \%)$ \\
\hline Topical route of drug administration & $95(34.42 \%)$ \\
\hline Drugs prescribed on fixed dose combination(FDC) & $127(46.01 \%)$ \\
\hline
\end{tabular}

Table -2 shows most commonly prescribed pattern of drugs 276 drugs and the number of mean drugs per prescribed 3.13. Total no. of Antibiotics prescribed 165(59.78\%), Oral route of drug administration 181(65.57\%), Topical route of drug administration 95(34.42\%).

Total no. of Antibiotics were prescribed 165(59.78\%).In this (Fig. 3) oral antibiotics 83(50.30\%), (Table -3) topical preparation antibiotics $82(49.69 \%)$ were prescribed. Fig. 3 showed Pattern of prescribed oral antibiotics. Out of these Amoxicillin + Clavulanic acid 46 (27.87\%), Cefixime 15(9.09\%) were the most commonly prescribed.

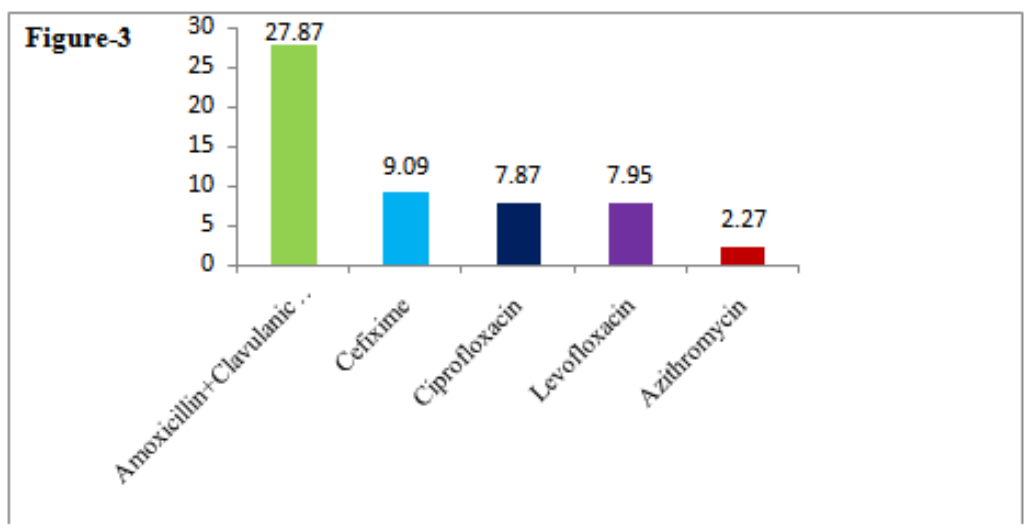

Fig. 3 Pattern of prescribed oral antibiotics. 
Table -3 Pattern prescribedof Topical preparation

\begin{tabular}{|l|l|l|}
\hline Drug name & $\begin{array}{l}\text { Topical preparation } \\
\text { prescribed }\end{array}$ & Percentage \\
\hline $\begin{array}{l}\text { Polymyxin-B sulphate+ Dexmethasone+ } \\
\text { Chloramphenicol }\end{array}$ & 53 & 32.12 \\
\hline $\begin{array}{l}\text { Clotrimazole+ Beclomethasone+ } \\
\text { Lignocaine }\end{array}$ & 10 & 6.06 \\
\hline $\begin{array}{l}\text { Ofloxacin+ Beclomethasone+ } \\
\text { Clotrimazole+ Lignocaine }\end{array}$ & 11 & 6.66 \\
\hline Ciprofloxacin+ Dexmethasone+ Lignocaine & 8 & 4.84 \\
\hline Total & 82 & 49.69 \\
\hline
\end{tabular}

Table -3 shows a total of 165(59.78\%) antibiotics, the highestprescribed topical preparation wasPolymyxin-Bsulphate+ Dexmethasone + Chloramphenicol-53(32.12\%)followed byOfloxacin+ Beclomethasone+ Clotrimazole+ Lignocaine-11(6.66\%) .

Table-4Pattern prescribed FDC drugs

\begin{tabular}{|l|l|l|}
\hline Drug name & No. of FDC prescribed n=127 & Percentage \\
\hline $\begin{array}{l}\text { Paracetamol+ } \\
\text { Phenylehrine+Anhydrasecaffine+Chlorpheneramine } \\
\text { Maleate }\end{array}$ & 71 & 55.90 \\
\hline Amoxicillin+Clavulanic acid & 46 & 36.22 \\
\hline Loratidine+Ambroxol & 05 & 3.93 \\
\hline Azithromycin+ Ambroxol & 2 & 1.57 \\
\hline $\begin{array}{l}\text { Diclofenac+serratopeptidase+ } \\
\text { paracetamol }\end{array}$ & 2 & 1.57 \\
\hline $\begin{array}{l}\text { Levocetrizine+Paracetamol+ } \\
\text { Anhydrase caffine }\end{array}$ & 01 & 0.78 \\
\hline Total & 127 & 100 \\
\hline
\end{tabular}

Table-4 shows atotal of 127(46.01\%) drugs were prescribed in FDC .Out of these ,highest prescribed FDC drugs were Paracetamol+ Phenylehrine+Anhydrasecaffine+Chlorpheneramine Maleate -71(55.90\%) and followed by Amoxicillin+Clavulanic acid-46(36.22\%).

Table-5Pattern of prescribing other medications

\begin{tabular}{|l|l|l|l|}
\hline Type of drug & Drug name & Total No. prescribed & Percentage \\
\hline Vit & Multivitamines & 07 & 2.53 \\
\hline Antihistamine & Levocetrizine & 07 & 2.53 \\
\hline Nasal decongestent & Xylometazolline & 07 & 2.53 \\
\hline Antiseptic & Povidineiodine & 06 & 2.17 \\
\hline Anti ulcer drugs & Pantopprazole & 02 & 0.72 \\
\hline
\end{tabular}

Table-5 shows other medications wereprescribed 16(5.79\%) in these Multivitamins,Xylometazolline, Levocetrizine $07(2.53 \%$ ) was the most commonly prescribed.

A total of 276 drugs, most commonly prescribed drug was

Paracetamol+Anhydrasecaffine+Phenylehrine+ Chlorpheneramine Maleate diclofenac+paracetamol 71(25.72), Chloramphenicol+ Polymyxin-B sulphate+ Dexmethasone 53 (19.20\%), Amoxicillin+Clavulanic acid $46(16.66 \%)$ were the most commonly prescribed drugs.

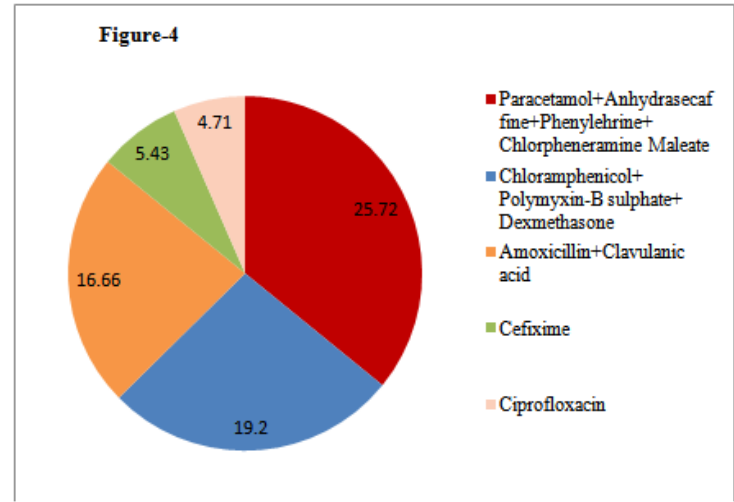

Fig:4 provide most commonly prescribed drugs in percentage. 
Table -6Incidence of polypharmacy

\begin{tabular}{|l|l|l|}
\hline No .of drugs/prescription & No. of prescriptions & Percentage (\%) \\
\hline Two drugs/ prescription & 07 & $6.50 \%$ \\
\hline Three drugs/ prescription & 63 & $56.25 \%$ \\
\hline Four drugs/ prescription & 17 & $15.17 \%$ \\
\hline Five drugs/prescription & 1 & $0.89 \%$ \\
\hline Without drugs & $24(112)$ & $21.42 \%$ \\
\hline
\end{tabular}

Table -6 shows about $56.25 \%(63 / 276)$ of the 3 drugs while $21.42 \% 24(112)$ of the prescriptions had no drug as those were conservative management patients.

The average number of drugs used in each prescription was 3.13. 56.25\% that is 63 per prescriptions were 3drugs.Fig -5 showed More than 45\% prescriptions the cost in between INR (Rs.) 101-150. Average cost per prescription INR 137.50 .

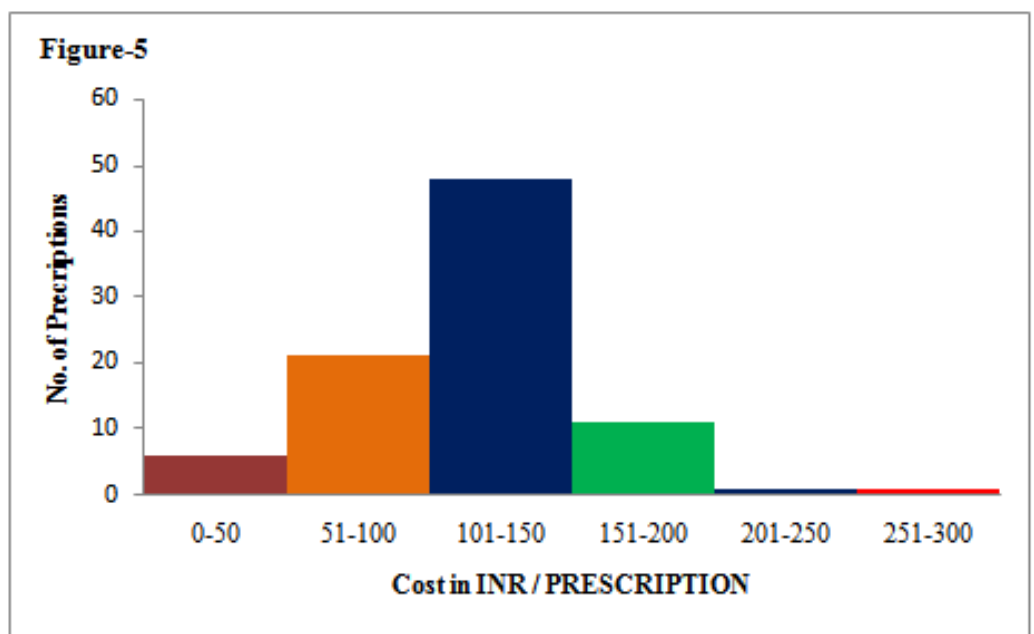

Fig:5 Cost analyses.

\section{Discussion}

In India incidence of CSOM ranges up to 30\%, with a prevalence rate of $16 / 1000$ population in urban and 46/1000 in rural areas. ${ }^{(11,12,)}$ The 112 CSOM infections patients, male and female patients who attended the OPD was 48(42.85) and 64(57.14) respectively,Females were more than male. The CSOM infections were more common in the age group of $11-40$ year who accounted for $74.10 \%$ (112) of the total patients. This study was comparable with the outcome of few authors BansalSulabhet alreported that male is to female ratio was found to be 1.2:1. Cases of CSOM were more common in females than in males, comparable with the outcome of few authors ${ }^{(13,14)}$ and in difference with other researchers. ${ }^{(15)}$

In the present study, it was observed that CSOM Safe active patients - 63(56.25\%), CSOM Unsafe patients $-25(22.32 \%)$ - which may be attributed to inadequate medical management of Eustachian tube dysfunctions at the peripheral level. Majority of the patients were from rural background. It may be an indicator of the inefficient health care delivery system, injudicious faith in the quacks and poor socioeconomic status. This is in concerned with the study conducted by (YadavPramilaet al, 2010) showing higher incidence of ear infections $50.8 \%$, followed by throat (31.37\%) and least were nose $26.47 \%$. The Doctor suggested to the Safe active patient - keep the ear dry, congervative management for ear i.e.Keep the cotton in the ear, prevent water entering the ear, avoid any type of nose \&throat infections, keep ear dry wait withdry ear for 3 weeks to make in inactive.

A prescription by a doctor may be taken as an indication of the doctors' attitude towards theDisease and the role of drugs in its treatment. The mean \pm SD number of drugs in our study was 3.13 . The average (mean) number of drugs per prescription is an important parameter while doing a prescription audit. A hospital based study in India had reported a mean number of two drugs. ${ }^{(16)}$ The mean number of drugs prescribed in this study is more was more than other studies reported in the literature. ${ }^{(17,18)}$ it is preferable to keep the mean number of drugs per prescription as low as possible since higher figures always lead to increased risk of drug interactions, development of bacterial resistance and increased cost. ${ }^{(19,20)}$ The number is however, higher than that reported in a previous study. ${ }^{(21)}$ Total no. of antibiotics prescribed165(59.78\%)The mean number of antibacterial agents prescribed per patient per course was found to be 1.87. In a similar study, Das et al, 2005 reported 1.4 antimicrobial agents per patient in outpatient services of ENT department in a tertiary care hospital of Eastern Nepal. It is an important indicator for assessing rationality of prescription. Hence, physicians should 
preferably keep the mean number of drugs per prescription as low as possible as higher figures always lead to increased risk of drug interaction, development of bacterial resistance and increased cost.The commonly prescribed oral antimicrobial agents83(50.30\%) were Amoxicillin + Clavulanic acid 46 (27.87\%), Cefixime $15(9.09 \%)$ were the most commonly prescribed,as indicated in ourStudy, could be due to an increase in antibiotic resistance which encourages physicians to choose a broader and safer option.

The common categories of drugs prescribed to CSOM outpatients were topical preparation antibiotics, Steroid combination ear drops wereused: 82(49.69\%).similar studyYadavPramilaet al, 2010reported topical preparations used were90 (26.70\%). The most commonly ear softeners used were combination of Polymyxin-B sulphate+ Dexmethasone+ Chloramphenicol53(32.12\%).Here the steroid given effectively reduces inflammation, granulation and mucosal edema. The anti fungals are added to prevent subsequent secondary otomycosis due to steroids.

The concomitant drugs were given the combination of paracetamol+phenylehrine+anhydrase caffine+chlorpheneraminemaleate71 $(55.90 \%)$ total of 127FDCAnti- pyretic like paracetamol was given to reduce the fever associated with most of the throat infection. It was given for its mild analgesic property. This would also avoid gastritis associated with analgesics. Analgesics were given for severe throat infection associated with pain, acute sinusitis and otitis externa. The most commonly prescribed analgesics were Paracetamol. The gastritis induced by analgesics were treated with anti ulcer drugs. Nasal decongestants and anti histamines symptomatically relieved the nasal congestion in case of rhinitis. Mucolytics were given in sinusitis, in combination with anti- histamines, also in case of acute otitis media, or sudden barotraumas to avoid the congestion. B complex tablets were given to patients who were on chronic treatment and in the treatment of aphthous ulcer.

Most of the patients were prescribed antibiotics based on presumptive diagnosis and clinical skills. All the patients were prescribed branded drugs. None of them received the generic drug. Prescription made by generic drug may reduce the overall drug expenditure. The average number of drugs used in each prescription was $3.13 .5625 \%$ that is 63 per prescriptions 3 drugs. Thus each prescription contains an antibiotic, antiulcer drug, an antihistamine/ analgesics on an average.The mean cost per prescription was in our study per day 137.50 Indian Rupees. In other study conducted by YadavPramilaet al 2010 cost per prescription is 105.In our study cost of prescription this may be due to high incidence of antimicrobial and brand name used.

Educational interventions to improve prescribing for doctors at different levels may be required. Such studies are necessary to obtain baseline data on drug use andcreate a database for comparison with future studies Implementation of educational programs to change the attitude of prescribers for improving drug utilization is the demand of present scenario. Standard therapeutic Guidelines can be formulated for the common ENT infections and followed universally; this would promote rational use of drug especially antimicrobial agents.

\subsection{The Doctor suggested to the patients following instructions:}

4.1.1. Safe active ear - keep the ear dry, conservative management with medicationsfor ear i.e. Keep the cotton in the ear, prevent water entering the ear, Avoid any type of nose \&throat infections, keep ear dry wait with dry ear for 3 weeks for surgical intervention.

4.1.2. Safe inactive ear- keep the ear dry, congervative management for ear i.e. Keep the cotton in the ear, prevent water entering the ear, avoid any type of nose \&throat infections, preanasthetic fitness, and prepare for surgery.

4.1.3. Unsafe ear -Aim to make ear safe .Car of the ear i.e. prevent water entering, avoid oil\& water, ear buds, Antibiotics for 7 days, ear drops, along with preanasthetic fitness for ear surgery (cortical/MRM).

\section{Conclusion}

There was no generics prescribed and efforts to encourage prescribing by generic name should be initiated. The average cost seems to be high. The data presented here will be useful in future, long-term and more extensive drug utilization studies in the hospital and in promotion of rational prescribing and drug use in hospitals. We recommend Regular CMEs for the doctors at different levels to encourage prescribing by generic names and on correct writing of prescriptions may be considered the use of FDCs was high. Educational interventions to improve prescribing for doctors at different levels may be required.

\section{Acknowledgements}

The help of Dr.Y.A.Deshmukh, Dr.sumanp.Rao, Dr.Ipseeta ray, Dr.yogesh Garje at the MGM College of Medical Sciences in the planning aspects of the study is gratefully acknowledged. 


\section{Reference}

[1]. Ahmadaa, Usman J, Hashim R, Isolates from CSOM, their antimicrobial sensitivity,Armed Forces Med J, 1999, 82-5.

[2]. Vartianien E, Effect of aerobic bacteriology on clinical presentation and treatment results of CSOM. J Laryngo-Oto, 1996, 315-8.

[3]. Altuntas A, Aslam A, Eren A. Susceptibility of microorganisms isolated from CSOM to Ciprofloxacin,Eur Arch Otorhino Laryngology, 1996, $364-6$.

[4]. Jakimovska F, Cakarm, Lazareveskia, et.al. CSOM -Microbiological findings. Balkan j otolneuro -otol, 2002, 104-6.

[5]. Sabella C. Management of otorrhoea in infants and children. Paed infectious dis J, 2000, 1007-8.

[6]. Alwotayan Rehab, AlabdulhadiKhaled. Otitis media: a review for the family physician. Bull Kuwait Inst Med specializat. $2003 ; 2: 83-89$.

[7]. Rupa V, Jacob A, Joseph A. CSOM: prevalence and practices among rural south indian children. Int J Pediatr Otorhinolaryngol.1999;48(3):217-221, May 25.

[8]. Laporte JR, Porta M, Capella D. Drug utilization studies: A tool for determining the effectiveness of drug use. Br J ClinPharmacol1983;16:301-4.

[9]. Krishnaswamy K, Kumar BD, Radhaiah G. A drug delivery percept and practices.Eur J ClinPharmacol1985; 29:363-70.

[10]. Gupta A, Gupta. A study of prevalence of complications of suppurative otitis media in rural area of Loni.Ind J Otol 1996;2:177-83.

[11]. Akinpelu OV, Amusa YB, Komolafe EO, Adeolu AA, Oladele AO, Ameye SA. Challenges in management of chronic suppurative otitis media in a developing country. J LaryngolOtol2008;122:16-20.

[12]. Mansoor T, Musani MA, Khalid G, Kamal M. Pseudomonas aeruginosa in chronic suppurative otitis media: Sensitivity spectrum against various antibiotics in Karachi. J Ayub Med Coll Abbottabad 2009;21:120-3.

[13]. Loy AH, Tan AL, Lu PK. Microbiology of chronic suppurative otitis media in Singapore. Singapore Med J 2002;43:296-9.

[14]. Poorey VK, Lyer A. Study of bacterial flora in csom and its clinical significance. Indian J Otolaryngol Head Neck Surg 2002;54:91-

[15]. Hede SS, Diniz RS, Agshikar NV, Dhume VG. Pattern of prescribed and OTC drugs in North Goa. Indian J Pharmacol1987; 19: 145-148.) 0601.78

[16]. Srishyla MV, Krishnamurthy M, Naga Rani MA, Clare M, Andrade C, Venkataraman BV. Prescription audit in an Indian hospital setting using the DDD (defined daily dose) concept.Indian J Pharmacol1994; 26: 23-28.

[17]. Rishi RK, Sangeeta S, Surendra K, Tailang M. Prescription audit: experience in Garhwal (Uttaranchal), India. Trop Doct 2003; 33: 76-79.

[18]. Atanasova I, Terziivanov D. Investigations on antibiotics in a hospital for a one yearperiod. Int J clin pharm ther1995;33:32-33

[19]. Till B, Williams L, Oliver SP, Pollans PI.A survey of inpatient antibiotic use in aTeaching Hospital.S Afr Med J1991;8:7-10.

[20]. Sarkar C, Das B. Prescribing trends in a teaching hospital in western Nepal. JNGMC 2002; 2: 4-7. 